\title{
The role of network density and betweenness centrality in diffusing new venture legitimacy: an epidemiological approach
}

\author{
James M. Bloodgood ${ }^{1}$ • Jeffrey S. Hornsby ${ }^{2}$. \\ Matthew Rutherford $^{3} \cdot$ Richard G. McFarland $^{4}$
}

Published online: 1 September 2016

(C) Springer Science+Business Media New York 2016

\begin{abstract}
To survive and grow, new ventures must establish initial legitimacy, and subsequently diffuse this legitimacy through a given population. While the notion of initial legitimacy has received substantial attention in the recent literature, diffusion has not. This work endeavors to outline the legitimacy diffusion process via drawing parallels with the field of epidemiology. Ultimately, to effectively diffuse legitimacy (and grow) a firm must gain positive judgments of appropriateness from members of a given network. Importantly, as with diseases, the characteristics of the network are critical to the diffusion process. A relatively dense network is posited to invoke a normative evaluation process by its members, and can be difficult for new ventures to access, but subsequent diffusion of new venture legitimacy can be rapid. A less dense
\end{abstract}

James M. Bloodgood

jblood@ksu.edu

Jeffrey S. Hornsby

hornsbyj@umkc.edu

Matthew Rutherford

matthew.rutherford@okstate.edu

Richard G. McFarland

mcfarland@essec.edu

1 Department of Management, College of Business Administration, Kansas State University, Manhattan, KS 66506, USA

2 Department of Global Entrepreneurship and Innovation, Henry W. Bloch School of Management, University of Missouri-Kansas City, Kansas City, MO 64110, USA

3 School of Entrepreneurship, Oklahoma State University, Stillwater, OK 74074, USA

4 Department of Marketing, ESSEC Business School, 3 Ave Bernard Hirsch, 50105 Cergy, 95021 Cergy Pontoise Cedex, CS, France 
network, on the other hand, is posited to invoke a pragmatic evaluation process by its members, and is likely easier for new ventures to access initially, but may result in lower levels of new venture legitimacy diffusion in the long run. Theoretical and practical implications are discussed.

Keywords Legitimacy D Diffusion - Network density · Epidemiology · Betweenness centrality $\cdot$ Legitimacy threshold

\section{Introduction}

Limitations associated with the growth and success of new ventures have long been held to stem from a liability of newness (Stinchcombe 1965). Oftentimes, this newness makes it difficult for new ventures to entice other stakeholders to engage in collaborative efforts or provide access to resources necessary for survival. New ventures that obtain legitimacy are better able to lessen their liability of newness. Although much of the ongoing legitimacy discussion has focused on existing organizations, discussion of the legitimacy of new ventures has been growing (c.f. Fisher et al. 2015; Überbacher 2014). Zimmerman and Zeitz (2002) described the dynamics of attaining initial legitimacy. Since then there has been a general acceptance that, before resource attainment can take place in a new venture, stakeholders must grant this initial base of legitimacy (e.g. Delmar and Shane 2004; Rutherford and Buller 2007).

Legitimacy diffusion gets at the notion that initial stakeholder endorsement must be leveraged to attract additional stakeholders who the new venture may be dependent on for survival and growth (Dacin et al. 2007; Kumar and Das 2007). Initial legitimacy, which occurs when others first begin to view the new venture as legitimate, must be leveraged quickly and expansively, so expediting the process is critical. As a simple example, consider a new software development firm that toils in survival mode until it lands a contract with Microsoft. Microsoft's clout likely establishes the initial legitimacy base for the young firm, and failure is deterred; however it does not ensure growth or long-term survival. To attain these outcomes, the legitimacy gained from the Microsoft contract must be leveraged to attract additional customers, employees, and financiers. In other words, it must be diffused; a critical process for new venture growth that extant research has inadequately addressed (Rutherford and Buller 2007).

Extending research on networks and venture legitimacy (Almobaireek et al. 2016), we submit that legitimacy diffusion is a function of characteristics of the stakeholder network, a primary element of the social context where legitimation transpires. The importance of the network has led the call for more research on the role of network structures in guiding organizational action (Stuart and Sorenson 2007; Obstfeld 2005). In extending the current literature. We ask the question: once initial legitimacy has been established for a new venture, what next? We argue that proactive assessment and targeting of particular types of network structures can provide new ventures with the ability to advance their legitimacy diffusion. We propose that network density and betweenness centrality affect the degree to which a network influences its members' decisions about new venture legitimacy. More specifically, the relative density and 
betweenness centrality of a venture's chosen network to promote itself will influence the type of sociopolitical judgment process (normative or pragmatic) used by network members to evaluate new venture legitimacy. Subsequently, the type of sociopolitical judgment process will influence the rate and extent of new venture legitimacy diffusion.

Network characteristics, such as density and betweenness centrality, also influence other socially-affected processes like disease epidemics. Thus, concepts from epidemiology may enrich understanding of new venture legitimacy diffusion. An important factor in epidemiology is the basic reproduction number $\left(\mathrm{R}_{0}\right)$ that denotes the number of susceptible individuals infected by a single individual. When this number reaches a key threshold, a disease will likely become an epidemic. Below this threshold, it will die out. Assessing this number beforehand to predict which diseases are likely to become epidemics is both difficult and valuable. The application to new venture legitimacy diffusion is intriguing and will be developed here. We proceed as follows. First, we describe new venture legitimacy, paying particular attention to a given entity's perception of a venture's legitimacy (i.e. legitimacy judgments) and exploring the notion of epidemiological thresholds. Next, we cover the network traits of density and betweenness centrality, and explain their role in the diffusion process. This will lead to our propositions.

\section{Theoretical overview}

\section{Significance of new venture legitimacy}

Low legitimacy of new organizations (Stinchcombe 1965) can lead to stakeholders' reluctance to work with a new venture because of uncertainty (Khaire 2010), a lack of desire to break existing practices with current partners, and potential social repercussions, which makes it difficult for new ventures to compete with incumbents (Hannan and Freeman 1984). Thus, promoting it as a better alternative to a competitor can be useful (Drori et al. 2009). However, deviating behaviors, with no socially-based legitimacy attached to them (Phillips et al. 2004), result in uncertainty and risk (Coleman et al. 1966) and an illegitimacy discount whereby the actions of a new venture may be regarded negatively (Zuckerman 1999). In addition, new ventures may be viewed as competence-destroying rather than competence-enhancing (Tushman and Anderson 1986) and could negatively affect incumbent organizations and cause them to avoid forming relationships with new entrants (Jensen 2008).

If legitimacy issues are overcome, a socially supportive environment is created that is conducive to venture growth (Doh et al. 2012; Baum and Oliver 1991). Thus, obtaining legitimacy is a worthwhile goal for new ventures. Something is judged legitimate when it appears appropriate in a (social) situation (Suchman 1995). The acceptance of a new venture by individuals or organizations that may provide resources, information, or cooperation to the new venture is critical; however obtaining legitimacy can be difficult. New ventures can initiate this process by using a variety of methods such as "symbolism" (e.g., Zott and Huy 2007), isomorphism (Suchman 1995), impression management (Nagy et al. 2012), deception (Pollack and Bosse 2014; Rutherford et al. 2009), pitching (Pollack et al. 2012), and identity development (Petkova et al. 2013). 


\section{Typologies of legitimacy}

While many typologies have been introduced in the literature, ${ }^{1}$ we submit that there are two key types of legitimacy judgments (Bitektine 2011; Aldrich and Fiol 1994) most relevant to new ventures, and we term them pragmatic and normative. Pragmatic legitimacy is legitimacy that is granted to firms based solely on a stakeholder's overt calculation of self-interest. Here, the stakeholder estimates a value to be received from a judgment of legitimacy and interacting with or enabling the new venture. This value often stems from the effect a venture's business model has on stakeholders such as customers and suppliers (Brettel et al. 2012). Higher expected values are more likely to lead to judgments of legitimacy. If a base judgment cannot be made, the venture will not be deemed pragmatically legitimate. Normative legitimacy, on the other hand, is associated with the firm's alignment with goals common to the social context, (e.g. profitability, job creation, providing useful goods). Judgments of normative legitimacy are based on the appropriateness of factors such as new venture goals and behaviors, which are filtered through a social lens to see if they are consistent with widely accepted beliefs and actions.

Both pragmatic and normative legitimacy are considered sociopolitical rather than cognitive. Cognitive legitimacy has a taken-for-granted nature among stakeholders requiring little if any active thought (Bitektine 2011). The more active nature of a sociopolitical approach to legitimacy evaluation usually requires more attentional resources devoted to collecting information and assessing the nature of an organization. We focus on the sociopolitical category of legitimacy because new ventures are typically different enough to warrant more than a cursory recognition of their legitimacy (Aldrich and Fiol 1994). Thus, although outliers may exist (e.g. Pollack et al. 2012), simply by seeking acceptance a new firm will trigger an assessment from the evaluator; and newness is generally understood as a "red flag" that triggers an evaluator's effortful due diligence. Pragmatic and normative legitimacy are based on prior works by institutional theorists, such as Suchman (1995) and Deephouse (1996), who adapted the notion of legitimacy from sociology (e.g. Weber 1947). In this literature, legitimacy is often discussed as an outcome of cultural support that can protect an existing firm from the external environment (Meyer and Rowan 1977). When considering legitimacy in a new firm, the focus shifts to the importance of attaining initial resources; and away from a method to mitigate negative externalities (Child 1972; Pfeffer and Salancik 1978). The importance of legitimacy in this setting has gained traction in the more recent literature (e.g. Aldrich and Martinez 2000; Choi and Shepherd 2005; Rutherford et al. 2009; Tornikoski and Newbert 2007; Zimmerman and Zeitz 2002).

\section{The diffusion of new venture legitimacy}

Having described new venture legitimacy and its initial attainment, we now examine legitimacy diffusion. Drawing on Tost (2011) and Bitektine (2011), we describe how individual stakeholders form legitimacy judgments. Importantly, both Tost and Bitektine (and others: Holt and MacPherson 2010; Pollack et al.

\footnotetext{
${ }^{1}$ For a complete review, see Bitektine (2011)
} 
2012; Zimmerman and Zeitz 2002) state that legitimacy-in the mind of a stakeholder-is dichotomous. This does not mean that all members of a network simultaneously judge an organization to be legitimate or not. Within a network, a new venture could have degrees of legitimacy which can be measured by the number of members that have judged that venture appropriate; either pragmatically, normatively, or both.

Diffusion of new venture legitimacy is the overall rate and extent to which stakeholders in a given network make positive judgments of legitimacy about a particular new venture. This is represented by the S-curve (or sigmoidal distribution) (See Fig. 1) that represents the number of individual units of a population that are in one of two states (e.g. yes or no). The left tail of this curve has been studied extensively, and we explain how the shape of it and the rest of the curve can vary depending on the type of population (network) the organization is part of.

Legitimation is the process whereby stakeholders make legitimacy judgments, within a social context, about a social object, and these feed into a collective set of judgments. This process is important for the current work, because new ventures are interested in encouraging additional stakeholders to move toward a judgment of legitimacy. Legitimacy diffusion is the rate and collective extent of legitimacy judgments that occur during the legitimation process. Of course both diffusion and legitimation are related to, but distinct from, the construct of institutionalization. Institutionalization is both a process and an outcome. Sometimes referred to as cognitive legitimacy or "taken-for-grantedness", it is a desired outcome that can be achieved by first achieving initial legitimacy and then diffusing that legitimacy profusely (Meyer and Rowan 1977). Thus defined it is unlikely to occur for our universe of new ventures. As noted above, in this context it is very difficult to achieve taken-forgrantedness.

\section{Legitimacy diffusion and epidemiology}

Research on new venture legitimacy has focused on its initial attainment-not its diffusion; therefore, we introduce and develop this notion of diffusion. There is a rich literature on diffusion in the medical field, primarily in the area of epidemiology, and as

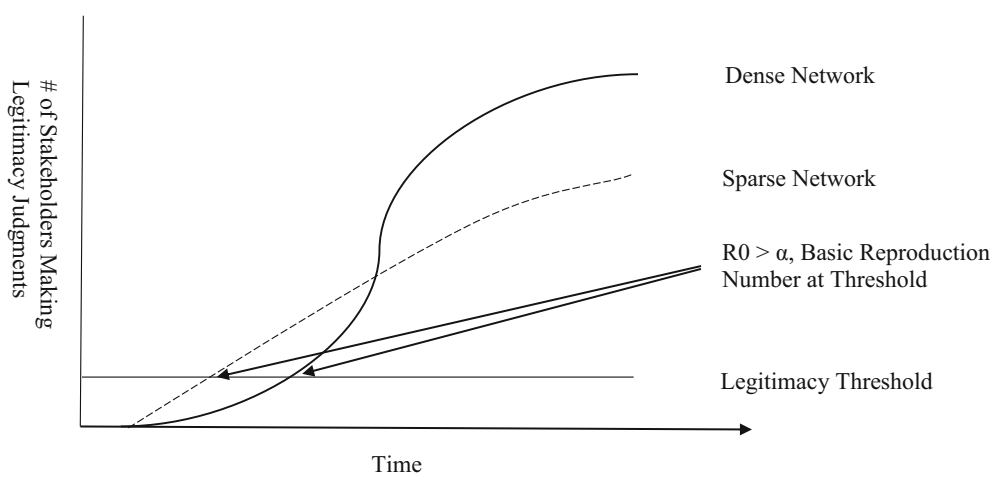

Fig. 1 Network-level legitimacy diffusion 
a field that has rigorously examined the process of diffusion for many years (e.g., Hernandez-Ceron et al. 2013; Hethcote 2009; Kermack and McKendrick 1927) it makes sense to examine the similarities occurring between the diffusion of disease and legitimacy. While there are differences, we maintain that there exist valuable insights in studying the foundational characteristics from epidemiology and applying them to the rubric of new venture legitimacy. There is precedent for marrying epidemiology and commercial diffusion. In fact, the widely cited and applied diffusion of innovations theory made popular by Rogers (1962); Rogers 1983, Rogers 1995; Rogers and Schoemaker 1971) is based in - and adapted from - this literature.

Epidemiology studies epidemics - diseases that affect many people and spread quickly among a population. This is precisely our concern here: legitimacy epidemics. We ask the question: under what conditions might a venture's legitimacy spread to the point of being an epidemic? While many factors play a role in diffusion variability, network properties are likely key to answering this question (e.g. Christakis and Fowler 2007). Network properties influence disease diffusion in a population (e.g. Kermack and McKendrick 1927), and epidemiologists consider these properties in mathematical models (e.g. Meyers et al. 2005). As an example, Myers and colleagues examined the faulty initial projections of the global SARS outbreak. They found a failure to account for heterogeneous networks in the prediction models led to an over-estimation of diffusion. This occurred because the initial analysis focused on hospitals and apartment buildings - closed, dense networks. Predictions from this data overestimate diffusion in more open networks. Most diseases typically have trouble spreading when humans are not in contact with one another. For instance, Riley et al. (2003) credit reduction in the number of face-to-face contacts in Hong Kong for limiting the spread of SARS. In social network terms, this is called reducing network density-by making networks more open. This is important because a key recommendation by experts during this epidemic was for members of the population to limit human contact.

\section{Basic epidemiology model}

The basic epidemiology model portrays the spread of a disease as being based on three general factors; the probability of infection if contact is made $(\tau)$, the rate of contact between infected and susceptible individuals (c), and the duration of infectiousness (d) (Anderson and May 1991); yielding the function:

$$
R_{0}=\tau \cdot c \cdot d
$$

The probability of infection if contact is made is primarily a function of the properties of the disease. The rate of contact between infected and susceptible individuals is generally a function of population density and/or role of the infected and susceptible individuals within the population of interest. The duration of infectiousness is primarily a function of the disease. In general, the greater each of these three variables, the faster and more extensive will be the exposure and transmission of the disease. Solving this function yields the basic reproduction number, which is critical to the study of epidemics and is similar to what entrepreneurship researchers have termed the "legitimacy threshold" (e.g Granovetter 1973; Navis and Glynn 2010; Rutherford and Buller 2007; Zimmerman and Zeitz 2002). Epidemiology focuses on thresholds. Specifically, 
when Kermack and McKendrick (1927) put forward the basic reproduction number, they stated that it could be used to determine an epidemic threshold. That is, when this number reaches a key threshold, that disease will likely become an epidemic. Below this threshold, the disease will die out. In general, when 1 infected person, on average, infects more than 1 person an epidemic is possible. When this number is below 1 , the disease will likely die out for stochastic reasons. A disease is treated vastly differently if the basic reproduction number exceeds 1 than if it is less than 1 .

In entrepreneurship, the legitimacy threshold (LT) has existed only conceptually. Using an epidemiology lens, we can measure it. Essentially, it is the number of people who need to be "infected" by a single transmitter for legitimacy to diffuse. Under the LT, the venture will not spread effectively and will die out. Over the LT, the new venture will diffuse and likely become an epidemic. Entrepreneurs want to reach this threshold before they run out of resources. Here, the epidemiological infection is the granting of legitimacy to a new venture. As new ventures may vary widely in their capacity to be perceived as legitimate (e.g. business model variation), we will hold constant the probability of infection if contact is made. In this case, when an "infected" stakeholder which has endorsed a new venture as legitimate makes contact with a "susceptible" stakeholder that has not, we assume there is an average likelihood of the susceptible organization subsequently endorsing the new venture as legitimate. ${ }^{2} \mathrm{We}$ also make the assumption that the duration of infectiousness, which is how long a stakeholder continues to endorse a new venture as legitimate once it has started to do so, can be held constant for our analyses.

Holding constant the probability of infection if contact is made and the duration of infectiousness allows us to parcel out the effects of the disease (new venture legitimacy) and to focus on the rate of contact between infected and susceptible individuals in influencing the rate and extent of new venture legitimacy transmission (diffusion). The rate of contact is likely to be significantly influenced by the density of organizations where contact may occur (Valente and Davis 1999) including the degree of social communication (Aunger 2002) associated with the social distance among organizations (e.g. degree of centrality). In particular, the extent of contacts within networks of organizations and the influence they have will vary with network density and centrality, and will likely influence cognitions and behaviors by others in the network. Dense networks create more opportunities for contact by network members and centrality decreases overall social distance such that network members can more closely perceive one another and their behaviors. These factors increase the influence among network members (via increased observation, communication, and sanctioning).

Innovation scholars have made similar observations with disease diffusion. Adoption and rejection of innovations diffuse throughout a network or social system, but social systems generate different rates of diffusion because of "norms and other system-level qualities" (Rogers 1995, p. 23). This difference stems from different structures in the social systems (DiMaggio and Powell 1983). Rogers (1995, p. 24) refers to structure as "the patterned arrangements of the units in a system". Moreover, he states that structure can "facilitate or impede the diffusion of innovations in a

\footnotetext{
${ }^{2}$ This average likelihood is probably fairly low in regards to new ventures, but as long as the rate does not approach zero or one the relationships posited here remain appropriate and relevant.
} 
system" (p. 25), but suggests that identifying how is difficult. To improve our understanding of these influences, we attempt to discern how structural characteristics of networks influence new venture legitimacy diffusion. Again, similar to disease diffusion, legitimacy diffusion follows the familiar S-curve, or a logistic function (see Fig. 1). This function describes the basic notion that a given phenomenon (e.g. disease, innovation, legitimacy) will grow very slowly at first followed by approximately exponential growth until it reaches saturation. This logistic distribution is important because it serves as a mathematical model unifying the study of disease and legitimacy. So, interchanging disease and legitimacy allows us to theoretically create a thread in the entrepreneurship literature: the diffusion of legitimacy, or the field's own form of epidemiology. Thus, based on the analogous relationship between the transmission of disease and the transmission of a social object (Aunger 2002) such as new venture legitimacy perception, epidemiology provides a useful way to organize our thinking about new venture legitimacy diffusion.

\section{The role of networks in legitimacy diffusion}

As previously alluded to, our explanation of new venture legitimacy diffusion centers on the role of networks. Networks, and clusters of organizations (Hospers et al. 2009), can have unique traits and offer valuable opportunities to organizations including new ventures. Networks are critical to diffusion because their members share information, provide visible judgments about new ventures, and provide a built-in social structure which motivates members through rewards and sanctions.

\section{Network density and betweenness centrality and new venture legitimacy diffusion}

The literature on entrepreneurial networks examines how they benefit new ventures. Stuart and Sorenson (2007) identified five mechanisms that explain how networks influence new ventures. The mechanisms are information access, brokerage, status, embeddedness, and sanctions. Integrating aspects of these mechanisms is important for explaining diffusion of new venture legitimacy. Although there are a number of factors that include these mechanisms, for reasons of parsimony, we narrowed our focus to network density and betweenness centrality. Our effort here is not to discount other factors, but to more fully explain how density and betweenness centrality influence diffusion.

Network density refers to the ratio of actual connections to the total possible connections within a network (Scott 1991). When the ratio is high there is high density and when it is low there is low density (also called sparse networks (e.g. Obstfeld 2005)). Most networks are likely to range between these two extremes (see Ritter et al. (2004) for examples of network foundations). To maintain consistency, we will refer to these two types of networks as high-density and low-density. Density varies in networks and influences the likelihood of independent actions, like funding a new venture.

Betweenness centrality can also differ among networks. Betweenness centrality measures a node's extent of lying in the connective paths of other network members (Newman 2005), but it can also act as a network measure by aggregating the individual network members' betweenness centrality. In this sense network betweenness centrality 
is the average shortest paths between network members. It denotes the potential speed and quality of observation and communication within a network. Although there is typically a positive relationship between density and betweenness centrality because each is affected by the number of connections in a network, betweenness centrality is more influenced by the existence and filling of structural holes within a network (Burt 1992). They cause network members to use more numerous, indirect connections to access other parts of the network. When structural holes are limited, because of connections between members in distinct parts of a network, the betweenness centrality increases and communication and observation among network members occur more easily and fully.

\section{Propositions}

Based on our earlier elaboration of networks and legitimacy, we propose a model (see Fig. 2) of how networks and legitimacy relate to one another. We start with a new venture's efforts to diffuse legitimacy by positively influencing stakeholders to view them as legitimate. This can be done via "supplying favorable categories and highlighting the relatedness of their new organizational form to well-established legitimate forms" (Bitektine 2011, p. 165), or by identifying uniqueness and relatedness (Petkova et al. 2013; Voronov et al. 2013) so that stakeholders view the venture as legitimate and it can have a better chance to establish relationships with them. Because most new ventures are not typically in a position to be viewed as cognitively legitimate, stakeholders will judge them using a normative or pragmatic evaluation processes (Aldrich and Fiol 1994; Tost 2011). We propose that the type of evaluation process used will be based on key network properties (i.e. network density and betweenness centrality). Ventures that attempt to diffuse via low-density/low

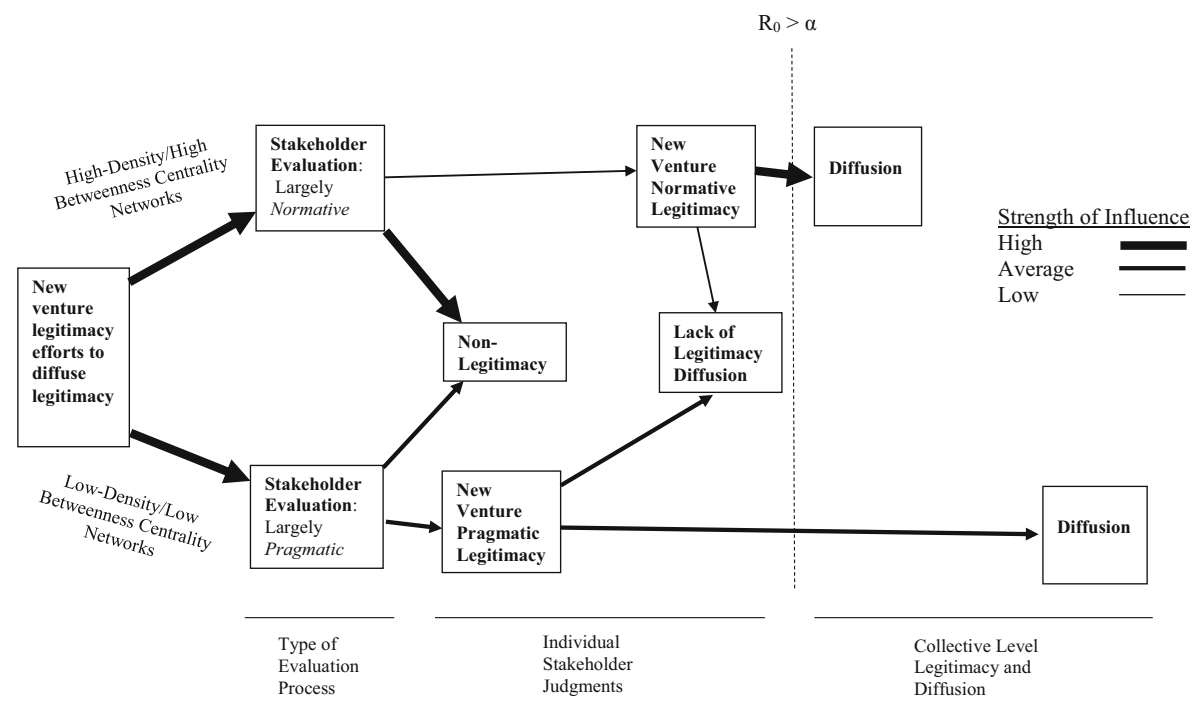

Fig. 2 Normative and pragmatic new venture evaluation processes 
betweeness centrality networks are likely to find these stakeholders making legitimacy judgments pragmatically, while new ventures attempting to diffuse in high density/ high betweenness centrality networks will encounter stakeholders making normative judgments. Other features of the model include a short line between stakeholder evaluation and the granting of pragmatic legitimacy. This indicates that individual legitimacy judgments can occur relatively quickly and easily in low-density/low betweenness centrality networks compared to high-density/high-betweeness centrality networks which have a longer line between stakeholder evaluation and the granting of normative legitimacy. Also, there is a short line between normative legitimacy judgments and diffusion and a longer line between pragmatic legitimacy and diffusion that indicate that, while both types of judgments may result in diffusion; after the threshold, high density/high betweenness centrality networks diffuse legitimacy more rapidly. To further illustrate that an epidemiologic threshold can occur more quickly in low-density/low betweenness centrality networks, we have noted the epidemiological threshold via a dashed line.

\section{Network properties and type of legitimacy judgment}

The epidemiology literature indicates that population density directly influences disease transmission (Aunger 2002), and is a key factor in determining whether a disease will become an epidemic (Ferguson et al. 2005; Meyers et al. 2005). Frequent contact, such as that found in dense populations, between infected and susceptible individuals provides opportunities for susceptible individuals to become infected. In the context of new venture legitimacy judgments among members of a network, dense networks with high betweenness centrality offer increased opportunities for interaction and information sharing about the new venture and network members (Bitektine 2011). These interactions and additional information sharing provide a foundation for increased socialization, where the perceptions and behaviors of members of a network can be influenced by other network members' words and actions. Thus, we propose a more socialized approach will be used by a network's members to evaluate the legitimacy of a new venture trying to gain acceptance by the network when there are more interactions among network members, such as those found in dense networks. Suchman (1995) provides a way to differentiate between less and more socialized environments by describing pragmatic and moral (which we refer to as normative) legitimacy. We can use his approach to describe the two processes for judging new venture legitimacy.

Suchman's (1995) view of pragmatic legitimacy contains three principal types: exchange, influence, and dispositional. Exchange legitimacy pertains to the expected value derived from, in the case here, viewing a particular new venture as legitimate. Influence legitimacy looks instead to the overall responsiveness of a new venture to the network member's general interests rather than particular benefits of viewing the new venture as legitimate. Dispositional legitimacy, on the other hand, has the network member focusing on the good nature of the new venture or its similarity to the network member. Together, these principal ways of evaluating a new venture take a relatively selfinterested, practical, and economic approach to judging new venture legitimacy. An approach that is not strongly influenced by other network members because of their ability to act alone and avoid social resistance (Adler 1981). For example, exchange 
legitimacy could be evaluated via a cost-benefit analysis that considers specific gains and losses the network member will receive or face from accepting or working with the new venture. Many of these factors could be unique to the network member so there is relatively little reason for the member to consider other members' input. If insufficient information is available for a specific cost-benefit analysis, the network member could look at how the new venture responds to its overall interests or how similar the new venture is to the network member in order to evaluate how likely in the future the new venture will act in ways beneficial to the network member. This inward-looking approach to new venture legitimacy judgment is not disturbed by other network members.

For Suchman (1995), normative legitimacy includes four types: consequential, procedural, structural, and personal. For our purposes here, consequential legitimacy considers the outcomes of the new venture. Existing accomplishments of the new venture are likely to be evaluated from a socialized perspective as network members discuss and interpret the new venture. Procedural legitimacy focuses more on how the new venture engages in its actions. The new venture is evaluated based on the specific processes it uses. Again, an understanding of these processes occurs in a social environment (network) as network members evaluate the appropriateness of the new venture's efforts. Structural legitimacy is determined more by the appropriateness of the characteristics and features of the new venture. Via a socialized perspective, network members come to understand the suitability of a new venture. Finally, personal legitimacy derives from the charisma of the new venture's representatives. Charisma can increase uncertainties as it is often used in change efforts and redefining the environment, and, therefore, network members will be more likely to look to each other for help in interpreting the appropriateness of a new venture. Overall, the more socialized nature of normative legitimacy evaluation of new ventures, as suggested by Suchman (1995), is consistent with the effects of a dense network and high betweenness centrality. Thus, we posit that network density and betweenness centrality use two conduits to influence new venture legitimacy perceptions among network members, extent of internal network contacts and internal network influence.

\section{Internal network contacts}

When network density and betweenness centrality are high, extensive contact among network members enhances cohesiveness through abundant opportunities for information sharing (Frazier et al. 2009). High density networks have well-established relationships among members of the network, which influence stakeholders to look to others for direction. In addition, Bitektine (2011) states that network members are likely to borrow others' judgments due to the principle of cognitive economy, which saves search and processing costs. Following others' lead in a dense network produces common understandings about the benefits of existing network beliefs and practices (Coleman 1988; Meyer and Rowan 1977) and can cause members to perceive new behaviors as illegitimate, thus maintaining or increasing the focus on current network practices (Portes and Sensenbrenner 1993). Thus, although legitimacy assessments are an individual-level decision, they can be significantly affected by collective-level factors.

Similarly, the overall structure of network member connections, via betweenness centrality, impacts the ability of a disease to reach susceptible individuals quickly and can effectively strengthen its transmission rate (Nigmatulina and Larson 2009). The 
degree of network betweenness centrality identifies the length of the shortest paths of transmission throughout a network (Freeman 1979). If betweenness centrality is high, the short paths mean that there are fewer susceptible individuals that need to become infected before all network members are exposed than when betweenness centrality is low.

\section{Internal network influence}

High network density increases influence among network members. Extensive communication improves information processing (Eisenhardt 1989) and makes known network members' behaviors. This pressures network members to conform to accepted network practices because members are aware when practices are not followed (Burt 2005). As a result, dense networks limit influence from outside the network (Burt 2005). DiMaggio and Powell (1983) also make this point when discussing institutional isomorphism as a source of similarity among organizations in an organizational field. A contributing factor is the increased interaction among organizations, such as is found in high-density networks. They identify three processes for this convergence; coercive, mimetic, and normative isomorphism. Coercive operates primarily through pressure, mimetic occurs as organizations try to deal with uncertainty, and normative occurs through professionalization of organizational members. We would expect all three isomorphic processes to contribute to network members' actionable views of new ventures, but with new ventures bringing in additional uncertainty it is possible mimetic isomorphism plays a considerable role in new venture legitimization. In addition, coercive isomorphism can also contribute as influence from other network members increases conformance pressures. As Schelling (1978) maintains, structured organizational fields result in their members responding to others' responses, which would distance a network member from pragmatic evaluation processes to more normative ones. Similarly, Jones (1984) illustrates via the famous Hawthorne studies that tightlygrouped individuals may disregard individual financial gain in favor of acting comparably to other group members.

As an example of pressure disparity Wu et al. (2013) found that even large, critical network members (e.g. Toyota) were inclined to avoid replacing underperforming suppliers if they are operating in a dense network. There is low social pressure present in less dense networks with lower betweenness centrality due to fewer connections among network members (Coleman 1988) but relatively more with those outside the network. This means that there is less comprehensive knowledge about the members within the network and relatively more novel information flowing into the network through external connections. The relative lack of knowledge about network members in these low-density situations provides an insufficient basis for generating social pressure and a collective culture is less likely to form (Rogers 1995). With higher betweenness centrality the transmission is assisted by more network contacts and greater internal network influence (Brass and Burkhardt 1992). In networks of high betweenness centrality, the filling of structural holes enables network members to communicate more directly. For example, in chain-type networks connections are only between adjacent network members. The only way for transmission to occur from non-adjacent network members is through intermediaries (Nigmatulina and Larson 2009). This indirect path slows down exposure because there are fewer direct contacts between some members of the network and there is less 
opportunity for the use of direct influence within the network. Social pressure is therefore more difficult to apply and less effective.

Stuart and Sorenson asked the question, "how do fledgling firms gain initial entry to established networks ...?" (2007, p. 212). They pointed to the social mechanisms in networks that influencing new venture network entry. We argue that when extensive social pressure exists within a network it leads to a greater reliance on normative judgment, and when there is little social pressure within a network it leads to a greater reliance on pragmatic judgment. Extensive contact among network members increases the influence they have over one another and this pressure causes socially-accepted thoughts and practices within the network to remain stable once they become established (DiMaggio and Powell 1983). In addition, this contact increases the monitoring of network members' actions which enhances the desire for compliance with network "rules" in order to maintain social legitimacy (Dacin et al. 2007). Therefore, the greater the network density, the less likely that stakeholders will engage in pragmatic judgment. Less dense networks, on the other hand, provide greater access to non-redundant information than do higher density networks (Granovetter 1973). With more unique information and less social pressure to conform, network members make more economically pragmatic decisions that may be different from the decisions of other network members.

P1a: In networks with higher density/higher betweenness centrality, stakeholders will be more likely to judge legitimacy via a normative process.

P1b: In networks with low density/lower betweenness centrality, stakeholders will be more likely judge legitimacy via a pragmatic process.

\section{Network properties and the epidemiologic threshold}

The spread of an idea or practice is affected by the flow of information or influence among connected nodes of a network (Borgatti and Foster 2003). In the case of legitimacy, some networks will possess characteristics that promote its spread (e.g. reflecting an asset of newness (Choi and Shepherd 2005)). New venture legitimacy may take on a contagious quality (i.e. high reproduction number) that is similar to what Coleman et al. (1966, p. 96) described as a "chain reaction" or "snowball" and has been denoted as "contagion of legitimacy" (Zucker 1987, p. 446) such that there is a rapid spread of legitimacy through a population (e.g. Baron 1998). An example is the recent popularity and success of Uber. Alternatively, other networks will act to diminish diffusion (Strang and Meyer 1994) leading to a slow spread of legitimacy (i.e. stakeholder to stakeholder) with a low basic reproduction number that causes a venture to likely die out. This is consistent with the liability of newness. The force of transmission of legitimacy viewpoints is initially similar for pragmatic and normative evaluators. A new venture attempting to make its case for legitimacy portrays itself as worthy of consideration with whomever it interacts. The difference, initially, is the barriers that are created by the receiver. Pragmatic evaluators will look to the selfserving advantages and disadvantages of the new venture to determine legitimacy. Normative evaluators, on the other hand, strongly consider the positions of other network members. Social-based judgments (Weber 1978) like these influence network 
members' verdicts about a new venture's legitimacy. Initial attempts by new ventures are often met with rejection under normative evaluation because a network member sees that other members are currently not viewing the new venture as legitimate. To remain in good standing within the network, and to avoid sanctions by other network members, users of a normative evaluation of a new venture will be initially hesitant to perceive the new venture as legitimate. Thus, because dense networks provide a hampering effect on normative judgments of new ventures (Welter and Kautonen 2005), a new venture stands a better chance of gaining initial legitimacy when pragmatic evaluation occurs. For example, Finne and Holmström (2013) found that systems integrators were able to gain entry into the supply chain network as legitimate new entrants due to the efficiency benefits they could provide to customers.

Normative judging, on the other hand, compares a new venture with established beliefs in the network (De Clercq and Voronov 2011). In the network the degree of social pressure often revolves around stability (Phillips et al. 2004). Although the degree of newness and novelty in each venture will vary (Bhave 1994), they may be unknown or offer new ways of doing things that may go against network protocol. Thus, when high social pressure leads to normative judgment, it will likely be toward not rendering the new venture as legitimate. For example, Wu et al. (2013) found customers in a dense supply chain network unwilling to consider new suppliers even when existing suppliers were performing below par. The normative judging in the dense network precluded judging new suppliers as legitimate.

Furthermore, normative evaluation means that network members are tightly coupled with less permeable relationships which can close them off to new ideas and change (Greenwood and Hinings 1996), thus increasing conformance. Network members risk their own legitimacy if they engage in the change, and are therefore more likely to avoid the change (Ahmakjian and Robinson 2001). Because of their social prominence within the network, these organizations are less able to hide within the safety in numbers and less inclined to attempt change unless their performance is poor (Boeker 1997) or below aspiration levels (Greve 1998). In normative evaluation, the high social pressure and high normative judging result in less opportunity for disharmony between network beliefs and a new venture's offerings.

P2: In networks with higher density/higher betweenness centrality, the epidemic threshold will occur more slowly than in networks with lower density/lower betweenness centrality.

A central principle in epidemiology can be used to examine the effects of pragmatic and normative evaluations on the rate and extent of new venture legitimacy diffusion. The principle is that transmission of a disease is based on the force of transmission overcoming any barriers (Aunger 2002). For example, highly infectious diseases have a strong force of transmission and individuals who isolate themselves to avoid the disease (Read et al. 2008), create significant barriers. We can look at forces and barriers to legitimacy transmission when examining differences between pragmatic and normative evaluation of new venture legitimacy. We argue that these forces and barriers change over time depending on the success of the legitimacy transmission. Epidemiology literature incorporates the idea of thresholds being a turning point for disease diffusion of a contagious nature (Nigmatulina and Larson 2009). The idea is that once enough 
infections occur the remaining susceptible individuals are highly likely to become infected. In the legitimacy literature, the idea of legitimacy thresholds has been raised in a similar manner. Zimmerman and Zeitz (2002) explained how reaching a legitimacy threshold provides a new venture with the ability to gain additional legitimacy; and as more network members observe this they will seek information from other members about the appropriateness of the new venture (Greve 1995; Kraatz 1998), and similarly assess the new venture (March 1981). Thus, "legitimacy begets legitimacy" (Rutherford and Buller 2007, p. 79) as more organizations follow early legitimacy judgers.

For example, when using a normative evaluation process extensive information interpretation and trust among dense network members increases the perceived appropriateness of network practices and the social pressure to use them (Soh 2010; Wong and Boh 2010), thus helping them to persuade one another to render legitimacy (Brass et al. 2004; Goldenberg et al. 2009; Mors 2010). This reduces the pragmatic appraisal of these practices, making them more difficult to question (Green et al. 2009), and increasing the social pressure and interest (Adler 1981) to use them. In this case, once legitimacy is achieved by a new venture the legitimacy can quickly diffuse. The dense network S-curve in Fig. 1 illustrates this concept by showing how a new venture that begins to be accepted will very quickly be endorsed via social pressure and normative judgment (Zimmerman and Zeitz 2002), thereby amplifying the diffusion process (Weick 1979). Thus, after organizations in the network judge a new venture as legitimate, it is likely to become legitimated at a faster rate (Leblebici et al. 1991).

If views of a new venture's legitimacy begin to penetrate a network, there is the potential for transmission barriers to drop significantly and the force of transmission to increase (i.e. via network members). The more positive views permeate a network, the more pronounced these effects are within the network. Similarly, epidemiology researchers often recognize that human behavior reflects changes in diffusion over time in their models (e.g. Nigmatulina and Larson 2009). This principle reflects the crossing of individual and collective levels that is instrumental in developing the epidemiologically-supported relationships we suggest here - that the collective network influences the network member and, in return, the network member influences the network by adding to the aggregating legitimacy assessments. We propose that this effect is stronger in normative evaluations of new venture legitimacy.

For a pragmatic evaluation, however, there is little change since the assessment of legitimacy is based on the advantages and disadvantages of the new venture rather than what other network members are doing. Thus, from an epidemiological perspective the barriers and force of transmission remain stable with pragmatic evaluation. It is different for normative evaluation. As more network members come to view the new venture as legitimate, their views are shared and network members will see this change and be more likely to acquire a similar view as they seek to remain in good standing in the network and avoid sanctions from network members (Barbalet 2014). Not only do the barriers to transmission drop, but the force of transmission increases as more network members begin to speak positively about a new venture. In this case, not only is the new venture trying to make a case for its legitimacy, but network members may join the chorus of promoting its legitimacy. This increases pressure on network members to view the new venture as legitimate. Thus, once sufficient numbers of members of a network begin to view a new venture as legitimate the use of a normative evaluation 
process will result in a significantly increased rate of legitimacy diffusion within the network relative to when a pragmatic evaluation process is used.

Exactly how a new venture starts in a dense network is puzzling given the significant tendency of the network to avoid change (i.e., initially legitimating a new venture). Adler (1981) provides a sequential model of (social) momentum that identifies possible sources of a spark, including individuals initially acting alone, but focuses more on the carrying out of the social momentum as it overcomes resistance. Koppenjan and Klijn (2004) identifies a variety of approaches to promoting a change including redefining the network, changing interaction processes, and modifying evaluation criteria. Although these can be more strategic in nature, their source can also be from external pressures. Some likely paths for instigating new venture legitimacy include new information (Bikhchandani et al. 1992) or new members with new ideas who have not been extensively immersed into the attitudes and behaviors of the network. Obviously, if there are very many new members at one time, the characteristics of the dense network would likely be lessened. This can result in an opening for a new venture to win over one or two members. Moreover, very few networks will use a wholly pragmatic or wholly normative process since those assume zero density or complete density, thus there is room for some dense network members to entertain a small degree of pragmatism in their evaluation process of new ventures. Although this small degree may be insufficient to challenge the status quo in the network in general, in time certain network members could begin to "see" the benefits of the new venture. It is these network members that should be of most interest to new ventures seeking legitimacy of a particular network as they afford the greatest potential for initially being viewed as legitimate in the network. New ventures could target these network members and enhance their perceived value in an effort to have positive outcomes of a smaller pragmatic process outweigh the negative ones from the normative process. Additional methods could include disrupting normative processes by disturbing routine patterns (Schelling 1978) of communication in the network and promoting the creation of cliques in the network that are potentially favorable toward the new venture. These methods could result in reduced normative processes until such time the new venture gains legitimacy, and in the case of cliques, could provide the means for the emergence and growth of support (similar to Weick's (1979: 15) "Majority Rule").

Most of the prior description of legitimation and diffusion has been written in the context of dense networks with the implicit understanding that the opposite would occur in less dense networks. To provide additional clarity, we briefly describe new venture legitimacy diffusion in a less dense network. Low density networks are less conducive to rapid diffusion (Coleman et al. 1966) because of less internal contact and influence within the network. This is portrayed by the smoother S-curve in Fig. 1. This smoothing stems from low-density networks questioning and comparing, from a pragmatic perspective, existing network practices and newly identified practices. This facilitates the experimentation with new ventures by organizations, but provides little opportunity for the legitimacy of any particular new venture to rapidly diffuse because legitimation is constantly weakened or at risk of termination. Members of less dense networks increase their focus on many new ventures which makes it possible for some pragmatic legitimacy to occur, but difficult for any particular new venture's legitimacy to become rapidly diffused. 
P3: In networks with higher density/higher betweenness centrality, once a threshold has been attained, diffusion will occur more quickly than in networks with lower density/lower betweenness centrality.

\section{Discussion and conclusion}

We began by asking the question of what happens after new venture legitimacy is established. Researchers have explored how organizations in general, and new ventures in particular, have sought and been judged to be legitimate. This is a valuable endeavor, but it only provides a beginning for identifying how new ventures are judged to be legitimate by groups of stakeholders. Conceptualizing the new venture legitimation process from individual to collective levels (and back) had not been accomplished. By relying on epidemiological principles, we believe that our effort here has made headway in the linking of individual and collective levels of the legitimation process for new ventures. We also believe that understanding the diffusion of new venture legitimacy is critical to researchers and practitioners because diffusion is an essential element of the growth and success of new ventures.

To address our research question, we developed a model and propositions that describe new venture legitimacy diffusion. We used network density and betweenness centrality to explain how the social context affects the diffusion process. We realize that other aspects of the social context need to be explored to continue to enhance understanding of the diffusion process. But, this first step was important because it extends the work of others on initial legitimacy judgments of new ventures. In advancing this line of research we used epidemiology as a guide and had to integrate multiple streams of research involving the areas of legitimation, network density, new venture legitimacy evaluation processes and judgments, collective level legitimacy, and diffusion. By organizing these research areas around individual and collective processes we constructed a model of new venture legitimacy diffusion that identifies different diffusion paths that stem from different social contexts that a new venture may seek out. This not only provides an explanation of how the process unfolds, but it points to the potential for entrepreneurs to influence their venture's legitimation process beyond the initial act of legitimacy-seeking via selection of legitimacy acquisition strategies (Zimmerman and Zeitz 2002).

\section{Theoretical implications}

There are two primary conceptual insights that arise from this work. The first is that the social structure of the potential stakeholders of the new venture may affect the type of legitimacy judgment process that occurs. We examined how the density and betweenness centrality of the network of stakeholders could influence the judgment process. We argued that a reliance on normative or pragmatic processes would stem from the existence of high- and low-density (and betweenness centrality) networks respectively. This gives rise to the idea that potential stakeholders do not have complete flexibility in how they evaluate new ventures. Their judgment process may be strongly influenced by their social context. This, of course, points to the 
likelihood that other aspects of the social context may influence the legitimacy judgment process, and these will also need to be examined.

The second conceptual insight is that the type of judgment process, normative or pragmatic, used may affect the rate and extent of legitimacy judgments. This effect occurs at both the individual and collective levels within a social context such as a network. Our logic and arguments directed us toward the idea that normative legitimacy judgment processes would be less likely to judge new ventures as legitimate initially, but if legitimacy judgments begin to be made by members of the network they would occur faster and more extensively than found in a pragmatic legitimacy judgment process.

These two conceptual insights extend the extant research focus that has primarily looked at identifying different types of legitimacy and possible strategies for new ventures to gain legitimacy. We add to these initial efforts by suggesting that the networks that new ventures try to gain legitimacy from have characteristics that will likely influence the type of legitimacy judgment process that will be used. Based on the process used, these networks will also likely vary in how quickly and extensively they may judge the new venture as legitimate. Thus, new venture growth and success may be closely tied to the types of networks in which they attempt to enter, rather than tied to particular firms in isolation.

In addition to these conceptual insights, an implication of our focus on network density and betweenness centrality is it highlights the lack of attention paid to network membership, structure, and boundaries. Our working assumption has been that networks are identifiable, but this is not always the case. Networks often contain members with various types of connections (i.e. multiplex (Burt 1980)), which means they are not all attached to the same degree. For example, in a supply chain network some network members are customers while others are suppliers depending on their location in the supply chain. Within a supply chain network, new ventures judged as legitimate by members at one level of the supply chain may not be judged as legitimate at another level. For example, if customers view a new manufacturer as pragmatically legitimate, in part, because they like the lower prices offered, suppliers to the new manufacturer might believe the low prices are not sustainable and the manufacturer will not last. Thus, the basic ideas of network membership need to take into account their potential fluidity.

Continuing with the idea that entrepreneurs may need to better plan out their legitimacy seeking efforts, the current research also informs stage and process models of entrepreneurship (e.g. Bhave 1994; Hanks et al. 1993). Researchers have noted the varying importance of networks during different entrepreneurial stages (e.g. Martinez and Aldrich 2011). Identifying what needs to be done at various stages of the entrepreneurship lifecycle often involves backing up from a predetermined completion point based on how long an activity requires (Fisher et al. 2015). Researchers interested in examining the benefits and drawbacks of entrepreneurs engaging in certain activities during particular stages may profit from a better understanding of the effects of the social context (Bloodgood et al. 1995). Some activities associated with gaining legitimacy and accessing resources or building external relationships may have to transpire in an earlier stage than previously thought. For example, a new venture in need of supplier-partners may have to start this process earlier when pursuing organizations in a dense or high betweenness centrality network. These same actions may not be necessary until a later stage if organizations in a less dense or low betweenness centrality network are the focus. 
Similar to stages, geographic levels should also be considered. Older stage models tended to view a new venture as developing locally first and then expanding regionally, nationally, and then globally. Although some ventures continue to follow this path, some new ventures start out globally. These are termed international new ventures (INVs) and are seen as marketing to or integrating resources from multiple parts of the world and gaining a competitive advantage using a product differentiation or low cost strategy (Bloodgood et al. 1996). From a legitimacy diffusion standpoint, each type of geographic expansion could benefit from a different approach. For instance, new ventures starting out locally or regionally may want to utilize local networks to a higher degree than would INVs because the networks might be more open to accepting the new venture.

\section{Research opportunities}

Legitimacy-related actions can influence performance (Khaire 2010; Rao et al. 2008). Thus, it is important to understand how legitimacy operates within networks. Our model offers several opportunities for future research. One opportunity is to examine if network density and betweenness centrality influence the type of legitimacy judgment process used by stakeholders. We argued that this influence occurs through the extent of internal network contact and influence. Empirical examination could be performed by measuring the density, betweenness centrality, extent of internal contact and influence of the networks where new ventures seek legitimacy judgments. Network members could be surveyed about how they specifically evaluate new ventures. This could determine the appropriateness of our model and help identify additional contextual factors that may influence the process. A second opportunity is to determine if initial legitimacy judgments are made more quickly in pragmatic judgment processes than they are in normative processes. Also, not all new venture efforts will be equally proactive in trying to obtain legitimacy judgments, so additional measures would need to account for this.

Another consideration is that the definition of legitimacy used within networks may vary and this might affect the attainment of legitimacy thresholds. Thus a third research opportunity is to see if rates of legitimacy attainment increase at different times for normative and pragmatic legitimacy processes. We have not explicitly theorized any differences. However, our implicit assumption that both processes would end up accumulating legitimacy judgments at certain rates would need to be confirmed.

A fourth opportunity is to determine if attaining normative-based legitimacy leads to quicker and more extensive diffusion than it does with pragmatic-based legitimacy. Although we conveyed a strong theoretical logic for why this would be the case, there could be reasons why it may not occur. Intervening variables may interfere with this effect. For example, a dense network that is facing significant technological change may find its members moving more toward a pragmatic evaluation process because of future uncertainties that outweigh social pressures. The opposite effect might also occur if network members lean on one another's views more because of uncertainties like technological change.

A fifth opportunity is to examine how venture characteristics affect the legitimacy judgment process. For example, the stage of venture development may be important for researchers to identify as it can significantly affect perceptions, behaviors, and 
outcomes for all organizations within a network. Ventures can be at various stages of development when they attempt to access networks and this may influence the typical processes used for evaluation. More developed ventures may be easier for network members to judge as legitimate which may affect the evaluation process and/or the diffusion rate.

Teasing out explanations for legitimation in any given situation is difficult (Green et al. 2009). For example, imitation stemming from normative legitimacy through contact and imitation arising from structural equivalence can be similar in effect, but very different in causality (Brass et al. 1998; Scott 1995). This provides opportunities for identifying specific causal mechanisms for various types of legitimacy judgment and diffusion in networks. For example, economic-based processes that are consciously performed, such as gap analysis, may enable researchers examine the interaction of social and non-social methods of determining organizational behavior (Seo and Creed 2002).

Additionally, the relationship between entrepreneurial experience and legitimacy diffusion in high- and low-density and betweenness centrality networks needs to be researched. Serial entrepreneurs may possess social capital that enhances legitimacy (Newbert and Tornikoski 2013). The entrepreneur's previous successes should mitigate resistance by dense or high betweenness centrality networks to judge a new venture as legitimate. In addition, researchers will also need to investigate how network density and betweenness centrality affect mediocre and inferior new ventures. Our focus was on potentially valuable new ventures, which are likely to have some merit-based acceptance. Inferior new ventures may be less likely to be accepted by each type of network. The extent of this acceptance, however, needs evaluation.

Related to the above point, tie strength between entrepreneurs and network members was not specifically addressed in the current research. Prior efforts by serial entrepreneurs are likely to create relationships that could contain a variety of tie strengths and these ties could influence views of legitimacy. Moreover, the tie strength can vary among network members in both dense and less-dense networks, and the tie strength could influence the transmissibility of legitimacy views. We strongly encourage future researchers to examine tie strength in both types of relationships to improve our understanding of new venture legitimacy diffusion. In addition, transmissibility of legitimacy views between networks can also be a critical factor in how diffusion occurs. Here we have focused on diffusion within a network, but diffusion throughout a population will likely involve many networks and the likelihood is great that this does not occur simultaneously. Instead, the sequential nature of some of the diffusion may identify the role that legitimacy views of one network can have on other networks.

Finally, although most of the research in the area of new venture legitimation has focused on judgments of legitimacy, judgments of illegitimacy are also important. Our model implicitly assumes that ventures can move from "not legitimate" to legitimate. However, they can also go from "not legitimate" to illegitimate; making it extremely difficult for a new venture to survive and grow. We did not address them in our model because illegitimacy has been insufficiently investigated. The lack of understanding in that area would make our model potentially cumbersome and imprecise. Our general view, however, is that illegitimacy judgments and diffusion are likely to follow a similar pattern to that of legitimacy. Thus, in a normative judgment process, if stakeholders start to judge a new venture as illegitimate, not just "not legitimate," the illegitimacy would diffuse quickly and extensively upon reaching an illegitimacy 
threshold relative to a pragmatic process. Given that illegitimacy has not been developed as much as legitimacy in the literature, we are not sufficiently confident to portray this in our model.

\section{Practical implications}

New ventures can enhance their chances for success by molding their strategy to the environment (Romanelli 1989; Venkatraman and Camillus 1984). In recognition of the conformance pressures that guide behaviors within networks, new ventures should consider actions to improve their chances for obtaining legitimacy within a network. New ventures do not have complete freedom to choose networks, and there is likely to be variance in even defining those networks (Mandják et al. 2011). Thus, they may not always be able to select the specific network that would be most beneficial to them. However, understanding the density and betweenness centrality of networks can guide new ventures as they develop relationships. Networks provide valuable resources and help (Hansen 1995; Shane and Cable 2002), but networking efforts take valuable time (Bloodgood et al. 1995) and are not always beneficial (Park et al. 2010). New ventures with limited knowledge and experience may use a "shotgun approach" for targeting networks. Take for instance the search for venture funding. After initially exploiting the friends and family network, ventures must penetrate the financial networks of banks and venture capitalists. Since these networks tend to be dense and hard to penetrate, many ventures pitch to all who will listen often resulting in unsatisfactory results. A more strategic initial approach of focusing on one member of the network could be very beneficial to overall legitimacy diffusion and venture acceptance. Depending on the current stage of legitimacy diffusion, a new venture may target networks that are high or low in density or betweenness centrality to hasten or enhance diffusion.

The following recommendations can assist new ventures that are free to choose their networks, and in preparation for how to deal with all networks - whether high or low density and betweenness centrality. First, new ventures should assess the density and betweenness centrality in a network. While networks that possess both either high or low density and betweenness centrality can be initially accessed by attempts at achieving pragmatic legitimacy, low-density and low-betweenness centrality networks provide an easier environment for initial legitimacy judgments of new ventures than do high-density and high-betweenness centrality networks because of independence among network members and limited concern about legitimacy (D'Aunno et al. 2000). Thus, in these networks a new venture may initially have an easier time forming relationships with some of these organizations because they are more receptive to economic-based logic or change that could enhance their performance. In high-density and high-betweenness centrality networks, social pressures from other network members tend to hurt new venture efforts toward achieving pragmatic legitimacy. This slower initial acceptance is important for new ventures to understand so they can plan more effectively. For instance, because different entrepreneurial behaviors are vital before and after achieving legitimacy (Rutherford and Buller 2007), new ventures may be able to shift their behaviors to those more conducive to growth rather than obtaining legitimacy. An understanding by new ventures of the role that social pressures will play in some networks may also help the new venture contest those pressures and improve its chances for initial legitimacy. 
Low-density and low-betweenness centrality networks provide an environment that is initially less contentious and disapproving of new ventures. Since time is often critical to new ventures (Choi and Shepherd 2004; Starr and Macmillan 1990), strategies that speed up acceptance are likely to improve performance. However, for new ventures that require high degrees of diffusion, those that need significant time may be better off focusing on dense or high-betweenness centrality networks as they offer the best chance for very high levels of diffusion. If this strategy is followed, the new venture may benefit from concentrating its efforts on key network members who, once they judge the new venture to be legitimate may trigger other network members to legitimate it (Rutherford and Buller 2007).

Another action for new ventures to consider is to forecast the future state of social pressure within networks of interest. Legitimacy varies over time (Dacin 1997) because interorganizational ties evolve continually, and this can affect the ongoing status of various elements of relationships, such as trust (Hite 2005). Trust in turn can influence the institutional forces that create and maintain social pressures. One factor that directly affects these ties is the turnover among boundary spanners. These individuals develop relationships between organizations (Gulati and Garguilo 1999), hence their entry and exit disrupts connections between organizations (Broschak 2004; Seabright et al. 1992).

\section{Epidemiology and entrepreneurship research}

We utilized epidemiological constructs and relationships to construct relationships involving networks of interest for new ventures. This effort informed and expanded new venture legitimacy beyond the stage of initial attainment. There is much more that can be done, of course. The two general factors of epidemiology that were not evaluated, but were controlled for instead, were the probability of infection if contact is made, and the duration of infectiousness (Anderson and May 1991). These also can be sources of guidance to researchers in entrepreneurship. Epidemiology suggests that certain characteristics of some diseases make them particularly infectious (e.g. spreadable through the air). Some business plans that are presented to interested stakeholders may be simple and appealing enough to be understood and spread easily while other plans may be complex and difficult to understand and spread. Researchers could examine the degree of stakeholder buy-in (disease transmission) among various types of business plans and the approach entrepreneurs use to present them. As far as the duration of infectiousness, researchers could investigate how long stakeholders remain interested in pursuing entrepreneurs once a stakeholder has accepted the premise of the new venture. If an entrepreneur's vision requires lengthy upfront investment and development before positive results appear, they may be better off constructing business plans that contain exponentially growing benefits that maintain interest among "infected" stakeholders even though the benefits will be undetectable for a long time. Researchers could investigate the degree of stakeholder withdrawal from new ventures to identify what types of benefits maintain the longest appeal.

In addition, although we focused on diffusion within certain types of networks, epidemiology also deals with how diseases move beyond a specific network. We proposed that new venture legitimacy would initially be harder to garner within a dense or high betweenness centrality network, but if a new venture begins to be perceived as legitimate within these types of networks the legitimacy will diffuse faster 
and more thoroughly than in low-density or low-betweenness centrality networks. What happens beyond the network is also of great interest to researchers and entrepreneurs. It seems logical that legitimacy diffusion within a dense or high-betweenness centrality network would influence the spread of diffusion beyond the network less than it would when the diffusion occurs in an open network. This could be examined using an epidemiological approach, whereby the degree of interaction between networks and the degree of similarity of the adjacent networks would be brought into the analyses. Thus, there is much more that epidemiologically-based analysis offers to the study of new venture growth.

\section{Limitations}

We must recognize some limitations of using an epidemiological approach to help explain new venture legitimacy diffusion. Above, we mentioned that the network to network spread of the legitimacy could also be investigated. We have focused on the spread of diffusion within a network, but epidemiology actually focuses on populations. This has been simplified in the model presented here, with an implicit understanding that the term "network" is not always clear cut. A population may not always be a set of distinct of networks. Rather, organizations in the population can be part of a number of networks and these networks can be based on a wide variety of commonalities and connections. It is hard to say where one network starts and another one ends. Even though there can be ambiguity surrounding the boundaries of networks in a population, it is still important to address this issue since it raises research questions concerning how networks overlap, interact, and how brokerage occurs between them.

An additional issue that is raised by the application of epidemiology is the use of a binary legitimate/not legitimate decision by network members. Epidemiology tends to focus on getting a disease or not getting a disease (although there can be variations), and we used this approach because it has support in the legitimacy literature. However, the decision to view a new venture as legitimate or not may not always be appropriate. There may be degrees of legitimacy in some situations. The simplistic model used here to examine the applicability of using epidemiological constructs to help explain new venture legitimacy diffusion, is only meant to be a start. Future research could investigate how degrees of legitimacy may affect the model.

Another issue is the potential for new ventures to be evaluated by network members can be much more complex that a general assessment of legitimacy. There can be a variety of dimensions that new ventures are evaluated on and the evaluations may be positive on some dimensions and negative or neutral on others. This was not captured in full in the model used here. An assumption is made that any specific dimensions of interest are evaluated simultaneously as part of the overall evaluation of legitimacy. This may not always be an accurate portrayal of legitimacy evaluations, and future research should take this into consideration. Some dimensions may be more or less important to different network members, and this can affect the socialization proposed here.

Our model has assumed a set of new ventures that are sufficiently different from network members such that they are not cognitively legitimated, but similar enough that they offer a potential, positive benefit to network members (in order to have a reasonable chance for gaining legitimacy). The degree of difference between a new venture and a network and its members could certainly influence the likelihood of new 
venture legitimacy diffusion, and these differences could be examined in future studies. There may even be an avenue to address this using epidemiology in the sense that disease transmission may depend on characteristics of the disease and certain physical or other characteristics of persons that could potentially be infected.

Finally, while the relationships posited here are focused on a few variables, we recognize that a variety of other factors may influence these relationships. Some of these factors could play a direct role in the model we present while others could play a moderating role. For example, issues of stage of development, geographic expansion, symmetry and directionality, and network types could significantly influence the degree to which density and betweenness centrality affect legitimacy evaluation processes used by network members.

\section{Conclusion}

The model of new venture legitimacy diffusion presented here integrates concepts from multiple research literatures including networks, new ventures, legitimacy, epidemiology, and diffusion. This integration provides the basis for an enhanced understanding of how new venture legitimacy is judged and diffused. The model incorporates individual and collective levels of analysis to extend our understanding of new venture legitimation. By presenting this model and propositions we hope to provide future researchers with a foundation for continuing to expand our understanding of the new venture legitimation process.

\section{Compliance with ethical standards}

Conflict of interest The authors declare that they have no conflict of interest.

\section{References}

Adler, P. (1981). Momentum. Beverly Hills: Sage Publications.

Ahmakjian, C. L., \& Robinson, P. (2001). Safety in numbers: Downsizing and the deinstitutionalization of permanent employment in Japan. Administrative Science Quarterly, 46(4), 622-654.

Aldrich, H., \& Fiol, R. (1994). Fools rush in? The institutional context of industry creation. Academy of Management Review, 19(4), 645-670.

Aldrich, H., \& Martinez, M. A. (2000). Many are called, but few are chosen: An evolutionary perspective for the study of entrepreneurship. Entrepreneurship: Theory and Practice, 25, 41-56.

Almobaireek, W. N., Alshumaimeri, A. A., \& Manolova, T. S. (2016). Building entrepreneurial inter-firm networks in an emerging economy: The role of cognitive legitimacy. International Entrepreneurship and Management Journal, 12, 87-114.

Anderson, R. M., \& May, R. M. (1991). Infectious Diseases of Humans: Dynamics and Control. Oxford: Oxford University Press.

Aunger, R. (2002). Exposure versus susceptibility in the epidemiology of "everyday" beliefs. Journal of Cognition and Culture, 2(2), 113-157.

Barbalet, J. (2014). The structure of guanxi: resolving problems of network assurance. Theory and Society, 43, 51-69.

Baron, R. (1998). Cognitive mechanisms in entrepreneurship: when and why entrepreneurs think differently than other people. Journal of Business Venturing, 13, 275-294. 
Baum, J. A. C., \& Oliver, C. (1991). Institutional linkages and organizational mortality. Administrative Science Quarterly, 36, 187-218.

Bhave, M. P. (1994). A process model of entrepreneurial venture creation. Journal of Business Venturing, 9(3), 223-242.

Bikhchandani, S., Hirshleifer, D., \& Welch, I. (1992). A theory of fads, fashion, custom, and cultural change as informational cascades. Journal of Political Economy, 100(5), 992-1026.

Bitektine, A. (2011). Toward a theory of social judgments of organizations: the case of legitimacy, reputation, and status. Academy of Management Review, 36(1), 151-179.

Bloodgood, J. M., Sapienza, H. J., \& Carsrud, A. L. (1995). The dynamics of new business start-ups: Person, context, and process. In J. A. Katz \& R. H. Brockhaus (Eds.), Advances in entrepreneurship, firm emergence, and growth (pp. 123-144). Greenwich: JAI Press.

Bloodgood, J. M., Sapienza, H. J., \& Almeida, J. G. (1996). The internationalization of new high-potential U.S. ventures: Antecedents and outcomes. Entrepreneurship: Theory and Practice, 20(4), 61-76.

Boeker, W. (1997). Strategic change: the influence of managerial characteristics and organizational growth. Academy of Management Journal, 40(1), 152-170.

Borgatti, S. P., \& Foster, P. C. (2003). The network paradigm in organizational research: A review and typology. Journal of Management, 29(6), 991-1013.

Brass, D. J., \& Burkhardt, M. E. (1992). Centrality and power in organizations. In N. Nohria \& R. G. Eccles (Eds.), Networks and organizations (pp. 191-215). Boston: Harvard Business School Press.

Brass, D. J., Butterfield, K. D., \& Skaggs, B. C. (1998). Relationships and unethical behavior: A social network perspective. Academy of Management Review, 23(1), 14-31.

Brass, D. J., Galaskiewicz, J., Greve, H. R., \& Tsai, W. (2004). Taking stock of networks and organizations: A multilevel perspective. Academy of Management Journal, 47(6), 795-817.

Brettel, M., Strese, S., \& Flatten, T. C. (2012). Improving the performance of business models with relationship marketing efforts-An entrepreneurial perspective. European Management Journal, 30, 85-98.

Broschak, J. P. (2004). Managers' mobility and market interface: the effect of managers' career mobility on the dissolution of market ties. Administrative Science Quarterly, 49, 608-640.

Burt, R. S. (1980). Models of network structure. Annual Review of Sociology, 6, 79-141.

Burt, R. S. (1992). Structural holes. Cambridge: Harvard University Press.

Burt, R. S. (2005). Brokerage \& closure. New York: Oxford University Press.

Child, J. (1972). Organizational structure, environment, and performance: the role of strategic choice. Sociology, 6, 1-22.

Choi, Y. R., \& Shepherd, D. A. (2004). Entrepreneurs' decisions to exploit opportunities. Journal of Management, 30(3), 377-395.

Choi, Y. R., \& Shepherd, D. A. (2005). Stakeholder perceptions of age and other dimensions of newness. Journal of Management, 31(4), 573.

Christakis, N. A., \& Fowler, J. H. (2007). The spread of obesity in a large social network over 32 years. New England Journal of Medicine, 357(4), 370-379.

Coleman, J. S. (1988). Social capital in the creation of human capital. American Journal of Sociology, 94, S95-S120.

Coleman, J. S., Katz, E., \& Menzel, H. (1966). Medical innovation: A diffusion study. Indianapolis: Bobbs-Merrill.

D’Aunno, T., Succi, M., \& Alexander, J. A. (2000). The role of institutional and market forces in divergent organizational change. Administrative Science Quarterly, 45, 679-703.

Dacin, M. T. (1997). Isomorphism in context: the power and prescription of institutional norms. Academy of Management Journal, 40(1), 46-81.

Dacin, M. T., Oliver, C., \& Roy, J.-P. (2007). The legitimacy of strategic alliances: An institutional perspective. Strategic Management Journal, 28, 169-187.

De Clercq, D., \& Voronov, M. (2011). Sustainability in entrepreneurship: A tale of two logics. International Small Business Journal, 29(4), 322-344.

Deephouse, D. L. (1996). Does isomorphism legitimate? Academy of Management Journal, 39(4), 1024-1039.

Delmar, F., \& Shane, S. (2004). Planning for the market: Business planning before marketing and the continuation of organizing efforts. Journal of Business Venturing, 19, 385-410.

DiMaggio, P. J., \& Powell, W. W. (1983). The iron cage revisited: Institutional isomorphism and collective rationality in organizational fields. American Sociological Review, 48, 147-160.

Doh, J. P., Lawton, T. C., \& Rajwani, T. (2012). Advancing nonmarket strategy research: Institutional perspectives in a changing world. Academy of Management Perspectives, 26(3), 22-39. 
Drori, I., Honig, B., \& Sheaffer, Z. (2009). The life cycle of an internet firm: Scripts, legitimacy, and identity. Entrepreneurship: Theory and Practice, 33, 715-738.

Eisenhardt, K. M. (1989). Making fast strategic decisions in high-velocity environments. Academy of Management Journal, 32, 543-575.

Ferguson, N. M., et al. (2005). Strategies for containing an emerging influenza pandemic in Southeast Asia. Nature, 437(7056), 209-214.

Finne, M., \& Holmström, J. (2013). A manufacturer moving upstream: Triadic collaboration for service delivery. Supply Chain Management: An International Journal, 18(1), 21-33.

Fisher, G., Kotha, S., \& Lahiri, A. (2015). Changing with the times: An integrated view of identity, legitimacy, and new venture life cycles. Academy of Management Review, amr.2013.0496.

Frazier, G. L., Maltz, E., Antia, K. D., \& Rindfleisch, A. (2009). Distributor sharing of strategic information with suppliers. Journal of Marketing, 73, 31-43.

Freeman, L. C. (1979). Centrality in social networks: conceptual clarification. Social Networks, 1(3), 215-239.

Goldenberg, J., Han, S., Lehmann, D. R., \& Hong, J. W. (2009). The role of hubs in the adoption process. Journal of Marketing, 73(2), 1-13.

Granovetter, M. S. (1973). The strength of weak ties. American Journal of Sociology, 78(6), 1360-1380.

Green, S. E., Li, Y., \& Nohria, N. (2009). Suspended in self-spun webs of significance: A rhetorical model of institutionalization and institutionally embedded agency. Academy of Management Journal, 52(1), 11-36.

Greenwood, R., \& Hinings, C. R. (1996). Understanding radical organizational change: Bringing together the old and new institutionalism. Academy of Management Review, 21(4), 1022-1054.

Greve, H. R. (1995). Jumping ship: The diffusion of strategy abandonment. Administrative Science Quarterly, 40, 444-473.

Greve, H. R. (1998). Performance, aspirations, and risky organizational change. Administrative Science Quarterly, 43, 58-86.

Gulati, R., \& Garguilo, M. (1999). Where do interorganizational networks come from? American Journal of Sociology, 104, 1439-1493.

Hanks, S. H., Watson, C. J., Jansen, E., \& Chandler, G. N. (1993). Tightening the life-cycle construct: A taxonomic study of growth state configurations in high-technology organizations. Entrepreneurship: Theory and Practice, 18(2), 5-29.

Hannan, M. T., \& Freeman, J. (1984). Structural inertia and organizational change. American Sociological Review, 49, 149-164.

Hansen, E. L. (1995). Entrepreneurial networks and new organization growth. Entrepreneurship: Theory and Practice, 19(4), 7-19.

Hernandez-Ceron, N., Feng, Z., \& Castillo-Chavez, C. (2013). Discrete epidemic models with arbitrary stage distributions and applications to disease control. Bulletin of Mathematical Biology, 75(10), 1716-1746.

Hethcote, H. W. (2009). The basic epidemiology models: models, expressions for R0, parameter estimation, and applications. Mathematical understanding of infectious disease dynamics, 16, 1-61.

Hite, J. M. (2005). Evolutionary processes and paths of relationally embedded network ties in emerging entrepreneurial firms. Entrepreneurship. Theory Into Practice, 29(1), 113-144.

Holt, R., \& MacPherson, A. (2010). Sensemaking, rhetoric and the socially competent entrepreneur. International Small Business Journal, 28(1), 20-42.

Hospers, G.-J., Desrochers, P., \& Sautet, F. (2009). The next Silicon Valley? On the relationship between geographical clustering and public policy. International Entrepreneurship and Management Journal, 5, 285-299.

Jensen, M. (2008). The use of relational discrimination to manage market entry: when do social status and structural holes work against you? Academy of Management Journal, 51(4), 723-743.

Jones, S. R. G. (1984). The economics of conformism. New York: Basil Blackwell.

Kermack, W.O. \& McKendrick, A.G. (1927). Contributions to the mathematical theory of epidemics. Proceedings of the Royal Society A, 115, 700; 138, 55; 141, 94.

Khaire, M. (2010). Young and no money? Never mind: the material impact of social resources on new venture growth. Organization Science, 21(1), 168-185.

Koppenjan, J., \& Klijn, E. (2004). Managing uncertainties in networks. London: Routledge.

Kraatz, M. S. (1998). Learning by association? Interorganizational networks and adaptation to environmental change. Academy of Management Journal, 41(6), 621-643.

Kumar, R., \& Das, T. K. (2007). Interpartner legitimacy in the alliance development process. Journal of Management Studies, 44(8), 1425-1453.

Leblebici, H., Salancik, G. R., Copay, A., \& King, T. (1991). Institutional change and transformation of interorganizational fields: An organizational history of the U.S. radio broadcasting industry. Administrative Science Quarterly, 36, 333-363. 
Mandják, T., Simon, J., \& Szalkai, Z. (2011). A framework for the analysis of global, regional and local business networks. Industrial Marketing Management, 40, 822-829.

March, J. G. (1981). Footnotes to organizational change. Administrative Science Quarterly, 26, 563-577.

Martinez, M. A., \& Aldrich, H. E. (2011). Networking strategies for entrepreneurs: Balancing cohesion and diversity. International Journal of Entrepreneurial Behaviour \& Research, 17(1), 7-38.

Meyer, J. W., \& Rowan, B. (1977). Institutionalized organizations: formal structure as myth and ceremony. American Journal of Sociology, 83, 340-363.

Meyers, L. A., Pourbohloul, B., Newman, M. E. J., Skowronski, D. M., \& Brunham, R. C. (2005). Network theory and SARS: predicting outbreak diversity. Journal of Theoretical Biology, 232, 71-81.

Mors, M. L. (2010). Innovation in a global consulting firm when the problem is too much information. Strategic Management Journal, 31, 841-872.

Nagy, B. G., Pollack, J. M., Rutherford, M. W., \& Lohrke, F. T. (2012). The influence of entrepreneurs' credentials and impression management behaviors on perceptions of new venture legitimacy. Entrepreneurship: Theory and Practice, 36(5), 941-965.

Navis, C., \& Glynn, M. A. (2010). How new market categories emerge: Temporal dynamics of legitimacy, identity, and entrepreneurship in satellite radio, 1990-2005. Administrative Science Quarterly, 55(3), 439-471.

Newbert, S. L., \& Tornikoski, E. T. (2013). Resource acquisition in the emergence phase: cConsidering the effects of embeddedness and resource dependence. Entrepreneurship: Theory and Practice, 37(2), 249-280.

Newman, M. E. J. (2005). A measure of betweenness centrality based on random walks. Social Networks, 27, 39-54.

Nigmatulina, K. R., \& Larson, R. C. (2009). Living with influenza: Impacts of government imposed and voluntarily selected interventions. European Journal of Operational Research, 195, 613-627.

Obstfeld, D. (2005). Social networks, the tertius lungens orientation, and involvement in innovation. Administrative Science Quarterly, 50, 100-130.

Park, Y., Shin, J., \& Kim, T. (2010). Firm size, age, industrial networking, and growth: A case of the Korean manufacturing industry. Small Business Economics, 35(2), 153-168.

Petkova, A. P., Rindova, V. P., \& Gupta, A. K. (2013). No news is bad news: Sensegiving activities, media attention, and venture capital funding of new technology activities. Organization Science, 24(3), 865-888.

Pfeffer, J. M., \& Salancik, G. R. (1978). The external control of organizations: a resource dependency perspective. New York: Harper \& Row.

Phillips, N., Lawrence, T. B., \& Hardy, C. (2004). Discourse and institutions. Academy of Management Review, 29(4), 635-652.

Pollack, J. M., \& Bosse, D. A. (2014). When do investors forgive entrepreneurs for lying? Journal of Business Venturing, 29(6), 741-754.

Pollack, J. M., Rutherford, M. W., \& Nagy, B. G. (2012). Preparedness and cognitive legitimacy as antecedents of new venture funding in televised business pitches. Entrepreneurship: Theory and Practice, 36(5), 915-939.

Portes, A., \& Sensenbrenner, J. (1993). Embeddedness and immigration: Notes on the social determinants of economic action. American Journal of Sociology, 98(6), 1320-1350.

Rao, R. S., Chandy, R. K., \& Prabhu, J. C. (2008). The fruits of legitimacy: Why some new ventures gain more from innovation than others. Journal of Marketing, 72(4), 58-75.

Read, J. M., Eames, K. T. D., \& Edmunds, W. J. (2008). Dynamic social networks and the implications for the spread of infectious disease. Journal of the Royal Society Interface, 5(26), 1001-1007.

Riley, S., Fraser, C., et al. (2003). Transmission dynamics of the etiological agent of SARS in Hong Kong: impact of public health interventions. Science, 300, 1961-1966.

Ritter, T., Wilkinson, I. F., \& Johnston, W. J. (2004). Managing in complex business networks. Industrial Marketing Management, 33, 175-183.

Rogers, E. M. (1962). Diffusion of innovations. New York: The Free Press.

Rogers, E. M. (1983). Diffusion of innovations. New York: The Free Press.

Rogers, E. M. (1995). Diffusion of innovations. New York: The Free Press.

Rogers, E. M., \& Schoemaker, F. F. (1971). Communication of innovations: a cultural approach. New York: The Free Press.

Romanelli, E. (1989). Environments and strategies of organization start-up: effects on early survival. Administrative Science Quarterly, 34, 369-387.

Rutherford, M. W., \& Buller, P. F. (2007). Searching for the legitimacy threshold. Journal of Management Inquiry, 16(1), 78-92. 
Rutherford, M.W., Buller, P.F. \& Stebbins, J.M. (2009). Ethical considerations of the legitimacy lie. Entrepreneurship Theory and Practice, July, 949-964.

Schelling, T. C. (1978). Micromotives and macrobehavior. New York: Norton.

Scott, J. (1991). Social network analysis: a handbook. London: Sage.

Scott, W. R. (1995). Institutions and organizations. Thousand Oaks: Sage Publications.

Seabright, M. A., Levinthal, D. A., \& Fichman, M. (1992). Role of individual attachments in the dissolution of interorganizational relationships. Academy of Management Journal, 35, 122-160.

Seo, M., \& Creed, W. E. D. (2002). Institutional contradictions, praxis, and institutional change: A dialectical perspective. Academy of Management Review, 27(2), 222-247.

Shane, S., \& Cable, D. (2002). Network ties, reputation, and the financing of new ventures. Management Science, 48, 364-381.

Soh, P. (2010). Network patterns and competitive advantage before the emergence of a dominant design. Strategic Management Journal, 31, 438-461.

Starr, J. A., \& MacMillan, I. C. (1990). Resource cooptation via social contracting: Resource acquisition strategies for new ventures. Strategic Management Journal, 11, 79-92.

Stinchcombe, A. L. (1965). Social structure and organizations. In J. G. March (Ed.), Handbook of organizations (pp. 142-193). Chicago: Rand McNally.

Strang, D., \& Meyer, J. W. (1994). Institutional conditions for diffusion. In W. R. Scott \& J. W. Meyer (Eds.), Institutional environments and organizations (pp. 100-112). Thousand Oaks: Sage Publications.

Stuart, T. E., \& Sorenson, O. (2007). Strategic networks and entrepreneurial ventures. Strategic Entrepreneurship Journal, 1, 211-117.

Suchman, M. (1995). Managing legitimacy: strategic and institutional approaches. Academy of Management Review, 20, 571-610.

Tornikoski, E. T., \& Newbert, S. L. (2007). Exploring the determinants of organizational emergence: A legitimacy perspective. Journal of Business Venturing, 22(2), 311-335.

Tost, L. P. (2011). An integrative model of legitimacy judgments. Academy of Management Review, 36(4), 686-710.

Tushman, M. L., \& Anderson, P. (1986). Technological discontinuities and organizational environments. Administrative Science Quarterly, 31, 439-465.

Überbacher, F. (2014). Legitimation of new ventures: A review and research programme. The Journal of Management Studies, 51(4), 667-698.

Valente, T. W., \& Davis, R. L. (1999). Accelerating the diffusion of innovations using opinion leaders. Annals of the AAPSS, 566, 55-67.

Venkatraman, N., \& Camillus, J. C. (1984). Exploring the concept of fit in strategic management. Academy of Management Review, 9, 513-525.

Voronov, M., De Clercq, D., \& Hinings, C. R. (2013). Conformity and distinctiveness in a global institutional framework: The legitimation of Ontario fine wine. Journal of Management Studies, 50, 607-645.

Weber, M. (1947). The theory of social and economic organization. New York: Oxford University Press.

Weber, M. (1978). In G. Roth \& C. Wittich (Eds.), Economy and society: An outline of interpretive sociology. Berkeley: University of California Press.

Weick, K. E. (1979). The social psychology of organizing. New York. NY: McGraw-Hill.

Welter, F., \& Kautonen, T. (2005). Trust, social networks and enterprise development: exploring evidence from east and West Germany. International Entrepreneurship and Management Journal, 1, 367-379.

Wong, S., \& Boh, W. F. (2010). Leveraging the ties of others to build a reputation for trustworthiness among peers. Academy of Management Journal, 53(1), 129-148.

Wu, T., Daniel, E. M., Hinton, M., \& Quintas, P. (2013). Isomorphic mechanisms in manufacturing supply chains: A comparison of indigenous Chinese firms and foreign-owned MNCs. Supply Chain Management: An International Journal, 18(2), 161-177.

Zimmerman, M. A., \& Zeitz, G. J. (2002). Beyond survival: Achieving new venture growth by building legitimacy. Academy of Management Review, 27(3), 414-431.

Zott, C., \& Huy, Q. N. (2007). How entrepreneurs use symbolic management to acquire resources. Administrative Science Quarterly, 52(1), 70-105.

Zucker, L. G. (1987). Institutional theories of organization. Annual Review of Sociology, 13, 443-464.

Zuckerman, E. W. (1999). The categorical imperative: securities analysts and the illegitimacy discount. American Journal of Sociology, 104, 1398-1438. 